Article

\title{
Sick Enough? Mental Illness and Service Eligibility for Homeless Individuals at the Border
}

\author{
Curtis Smith ${ }^{1, *(D)}$ and Ernesto Castañeda ${ }^{2}$ (D) \\ 1 Department of Sociology, Bentley University, Waltham, MA 02452, USA \\ 2 Department of Sociology, American University, Washington, DC 20016, USA; ernesto@american.edu \\ * Correspondence: csmith@bentley.edu
}

Received: 16 June 2020; Accepted: 10 August 2020; Published: 14 August 2020

\begin{abstract}
This paper measures mental illness among individuals experiencing homelessness in a border city and compares it to the general housed population. We use original data from a homeless survey conducted in El Paso, Texas. Respondents self-reported any possible mental illness or related symptoms. We find that mental illness is not disproportionally common among the homeless, yet this is something that is often claimed by laypersons, some social service workers, and some researchers that limit sampling to institutionalized settings where formal mental illness is often among the prerequisites for admission. We find that "severe mental illness" among homeless persons is $6.2 \%$ (only around 2-3\% higher than the general population), and "any mental illness" is 20.8\% (only 1-3\% higher than in the general population). Our results are consistent with other research focusing on street samples.
\end{abstract}

Keywords: homelessness; mental health; point in time; diagnosis

\section{Introduction}

Is the prevalence of mental health higher for people experiencing homelessness than among those who are housed? The visibility of mentally ill homeless individuals around universities or downtown areas may lead many to believe that mental illness is one of the leading causes of homelessness. This paper addresses mental illness among people experiencing homelessness in a city on the U.S.-Mexico border. The findings have methodological and policy implications.

Individuals experiencing homelessness who are not disabled enough have little access to public housing in the U.S. under Housing and Urban Development (HUD) programs. The U.S. federal mandate prioritizes "chronic" homelessness, which is defined to include those who have experienced homelessness for an extended period and also have disabilities:

The statutory definition also requires that the individual or family has a head of household with a diagnosable substance use disorder, serious mental illness, developmental disability, post-traumatic stress disorder, cognitive impairments resulting from a brain injury, or chronic physical illness or disability (HEARTH 2015, p. 75792).

Even among state and local municipalities, funding transitional or permanent housing of homeless individuals is often limited to target specific subpopulations, such as victims of domestic abuse, homeless children, those with mental illness, and other groups deemed the most deserving. Eligibility for housing is most often limited to those with a "verifiable disability," which neglects many others in need (Lyon-Callo 2000). Previous work shows how social service workers manage to "fit" their homeless clients into overly restrictive housing requirements by using "fitting stories" or narratives (Smith and Anderson 2018). This brings into question the prevalence of disabilities. As one supervisor 
put it, "if agencies are too stringent, then they don't help many people" (Smith and Anderson 2018, pp. 542-43).

We believe that the stereotype that a majority of people in homeless situations experience severe mental illness makes access to services more restrictive. Three beliefs contribute to this stereotype, (1) that the deinstitutionalization of people from state mental institutions constitutes the largest group of homeless individuals on the streets, (2) that there is a consensus among the literature as to how to study mental illness among this population, and (3) that there is a higher prevalence of mental illness among the homeless compared to housed populations. We challenge these beliefs in this paper.

Estimates of mental illness prevalence among homeless populations vary widely between studies. The related research spans fifty years, and our study is novel in two ways. First, studies that limit sampling homeless populations to include only those who are within institutionalized settings (shelters, transitional and permanent housing facilities, jails, prisons, and mental health facilities) have found higher rates of mental illness, some as high as 100\% (Fazel et al. 2008; Fischer 1989; Shlay and Rossi 1992; Lee et al. 2010). Nevertheless, many people avoid services (Canvin et al. 2007), and many homeless people avoid shelters and subsidized housing in general by staying on the streets instead (i.e., under bridges, in parks, an automobile, vacant buildings, or "doubled up" with someone willing to take them in). Emergency shelters can be avoided for a variety of reasons, including that they are overcrowded, noisy, among other things (Wasserman and Clair 2010). Research often neglects these subpopulations that represent a substantial part of the homeless population. In El Paso, TX, a city ranked 19th largest in the U.S. (City Mayors Statistics 2010), we counted 20\% more in the total homeless population by including individuals who did not stay in shelters (Smith and Castañeda-Tinoco 2019).

Some suppose that street samples include individuals who are avoiding the stigmas of their severe mental state, which may be the case for some. However, studies that sample beyond shelters and include street populations find far fewer cases of mental illness. Researchers in Austin, TX found 9\% of those living outside of shelters to be mentally ill (Snow and Anderson 1993). Researchers in Australia found $15 \%$ of respondents on the streets to have a severe mental illness before being homeless and $16 \%$ after experiencing homelessness (Johnson and Chamberlain 2011). Additionally, HUD's annual Point-in-Time (PIT) national count, which is the most referenced source by federal policymakers, routinely finds 30-33\% to be mentally ill, each year, over the past ten years (HUD 2007-2018 2019). Most prior research limits sampling to those already sheltered or are in institutional settings, including homeless shelters, jails, or hospitals. This approach neglects that mental illness is, "In line with the eligibility criteria" for service access (Aubry et al. 2015, p. 471). So people need to be disabled under the federal definition of "chronic" homelessness as a prerequisite to receiving housing assistance. For example, an annual review titled The Prevalence of Mental Disorders Among the Homeless in Western Countries: Systematic Review and Meta-regression Analysis (Fazel et al. 2008) shows that almost all studies devoted to the subject in the United States, Germany, United Kingdom, Australia, Greece, France, and Holland limit sampling to places where respondents are actively seeking housing services such as shelters, day centers, missions, or "facilities for the homeless" in almost all studies (a few include soup kitchens and hostels). Therefore, most literature-particularly quantitative studies—disregard homeless populations who avoid housing services. Alternatively, most noninstitutionalized street samples find substantially fewer homeless who are mentally ill, as we elaborate below.

Second, we use categories from the U.S. National Survey on Drug Use and Health (NSDUH), which studies domiciled (housed) populations, by distinguishing "serious mental illness" (SMI) from "any mental illness" (AMI). Some cases of AMI are not severe enough for access to housing services per HUD's definition of "chronic homelessness" (HEARTH 2015). Current homeless policy and existing research measure mental illness more generally in ways that lack distinctions between its various forms and levels of severity. We use NSDUH's distinctions of SMI and AMI, traditionally used for studying the "housed" population, to study those experiencing homelessness to delineate those who are eligible for housing (SMI) to those who are not "severe" enough. 
We modeled our homeless street census on the HUD annual Point-in-Time survey. We focused on homeless individuals with mental illness (SMI and AMI), stressing the necessity to gauge by severity because not all types of mental illness qualify for access into housing services under the current policy, which is a point often underestimated by prior research. For example, diagnoses of situational depression or other mood disorders do not qualify for housing vouchers under Continuum of Care funding, as noted below. We believe that people with less severe mental illnesses deserve housing assistance as much as those with more severe cases, which falls in line with those who advocate that housing is a human right (Bratt et al. 2006).

We start by summarizing two competing theoretical frameworks often used to explain this issue, commonly referred to as the "Deinstitutionalization" and the "Medicalization" of the homeless population. Next, we consider budgetary reductions of welfare assistance throughout the 1980s. We then outline how measuring mental illness among the homeless has been polemical due to various inherent methodological issues regarding whom to count. We demonstrate how methodologies commonly used to study homelessness produce an overrepresentation of mental illness while simultaneously underestimating how many homeless with mental illness qualify for existing services. To our knowledge, this study is the first to directly compare the severity of mental illness among the homeless to that of the domiciled (housed) population.

\section{Historical Arguments: Deinstitutionalization versus Medicalization}

Contemporary research on homelessness points to how cities prioritize efforts to "manage" homeless populations via mechanisms of control instead of housing them (Willse 2015). Some ethnographic work focuses on the details of the harsh policing of the homeless (Stuart 2016). Other research is framed around how to best provide housing for the homeless, focusing on the effectiveness of the "housing first" philosophy (Padgett et al. 2016; Chen 2019), while others point to the cost-effectiveness of prioritizing homeless populations with disabilities (Culhane et al. 2002). However, focusing on disabilities, particularly mental illness, has been a contested issue for decades.

In the 1980s and early 1990s, a drastic increase of visible homeless followed the deinstitutionalization of state mental facilities and President Reagan's budget reductions to welfare. This led to increased attention to homelessness (Kozol 1988; Stern 1984). Regan-era budget reductions included decreasing HUD's budget from over $\$ 65$ billion to just over $\$ 10$ billion (85\% reduction) and included massive rollbacks to such programs as Aid to Families with Dependent Children and food stamps (Kozol 1988). Cities like Chicago experienced a noticeable increase in their visible homeless, which grew by eight times from what was previously recorded and showed overall demographics change from single males to include females and families with children (Jencks 1994). Researchers following the 1980s influx of visible homeless call the phenomenon the "new homelessness," noting a more diverse "face" of homeless populations, which includes females, children, and families increasingly experiencing homeless spells (Lee et al. 2010; Rossi 1990).

Many social service providers, policymakers, and quantitative researchers often point to the process of deinstitutionalization from state mental hospitals to explain the massive increases in the homelessness population following the 1980s. Researchers since the 1980s (Jencks 1994) and more recently (Dear and Wolch 2014) have explained the process of deinstitutionalization as a process by which service-dependent populations do not have enough access to services in general. Jencks (1994) emphasizes five deinstitutionalization phases: (1) the late 1940s to early 1950s when federal policy reduced state mental hospitals that were deemed more harmful than beneficial to patients; (2) in 1965, Congress established Medicaid, state mental hospitals transferred their residents to nursing homes to save on cost; (3) in 1972, beneficiaries could gain Social Security Income (SSI) income, food stamps, and Medicaid totaling \$500/month, (4) in 1992, discharged patients from inpatient facilities for people experiencing mental health issues became immediately eligible for services following hospitalization; (5) restrictions on involuntary commitment followed the critiques in the works of Thomas Zsasz and Erving Goffman on psychiatry and asylums, respectively (Goffman 1962; 
Jencks 1994). Edwin Fuller Torrey (1988) also chronicles the process of deinstitutionalization of patients from state mental facilities by saying that the numbers peaked $(500,000)$ during the 1950 s and were halved (less than 200,000) by 1970, which is over a decade before increases of visible new homeless were noticed during the 1980s, and official national homeless counts began.

Following the 1980s, research on homelessness attempted to explain demographic changes among the new homeless populations. Some researchers argue that empirical evidence did not support the claim that deinstitutionalization was the primary driver of homelessness in the 1980s. Snow et al. (1986) provided a multi-prong critique: (1) noting the timing discrepancy between deinstitutionalization and evidence of the new homeless populations, (2) questioning how researchers created estimates of the mentally ill, and (3) pointing to structural issues such as poverty, unemployment, reduced welfare benefits, and increased cost of housing as playing more dominant roles than mental illness in expanding the homeless population. Researchers were forced to consider contextual factors beyond the traditional single male homeless "old hobo," as they were called in the 1920s, or distinctly the "hobohemia" period before the era of the new homelessness (see Anderson 1923).

Researchers still argue over the causes of the increase in homelessness since the 1980s. While some point to the deinstitutionalization of state medical hospitals, others point to structural issues of welfare reductions that caused social service agencies to scramble for limited available funding to continue operations under a medicalized framework (Huey et al. 2012; Lyon-Callo 2000). Some argue, more generally, of a combination of structural issues, policy changes, institutional failures, and individual vulnerabilities as proximal and distal causes (Gaetz 2020). Surveys of homeless populations conducted during the 1980s, such as those of Fischer (1989), found consistently high rates of addiction and mental health problems, particularly among single men. However, research has since found biases in their measurement of reported mental illness because rather than focusing on respondents' current experiences, as is the norm for other populations, they recorded experiences during the lifespan of homeless individuals (Snow and Anderson 2001; Snow et al. 1994; Snow et al. 1986). Homeless populations are often studied differently than domiciled populations. Building on what Conrad (1992) calls the "medicalization of society," researchers provided critical analysis of how homelessness is framed. Research also found that claims of high rates of reported mental illness among those experiencing homelessness were swayed by social exchanges with intake workers and insurance billing demands (Braun and Cox 2005; Lyon-Callo 2000).

It is crucial to consider how those experiencing homelessness access services. Bogard (2001) explores popular stereotypes about homeless individuals and the conceptual construction of homelessness, arguing that contextual indicators produced the contemporary homeless situation. By comparing New York City to Washington, DC from 1977-1981, she argues that a more structure-focused housing approach took place in Washington, DC. This was overcome by a medicalized version of defining homelessness in New York City, which inspired homeless policies throughout the U.S. (Bogard 2001). She notes that this divergence is represented in the academic literature about homelessness, where some scholars focus a majority of attention on pathological shortcomings of homeless individuals while others focus on broader contextual factors (Bogard 2001). She emphasizes that those focusing on pathological shortcomings are individualizing responsibility, like the New York model, and advocate for a strong therapeutic intervention and an increase in related services. However, others draw attention to structural issues, like the DC model, which includes rising housing markets and income inequalities, all of which should be remedied through public policy and not focus on personal impairments of homeless individuals. Two separate meta-analyses find inadequate wages and the rising cost of housing as persisting causes of homelessness (Lee et al. 2010; Shlay and Rossi 1992).

The extent that mental illness drives people into homelessness should be compared to what percentage of the homeless population has a mental illness. Symptoms may appear after experiencing living rough (outside). There is an ongoing debate over the prevalence of mental illness among those experiencing homelessness due to the various contexts in which it is measured (Fazel et al. 2008) and lingering methodological problems of measurement (Susser et al. 1990). Findings are inconsistent and 
range between 4-100\% (Fischer 1989; Lee et al. 2010; Shlay and Rossi 1992). This wide range may be due to different sampling frames. Studies that survey shelter inhabitants find far higher amounts of mental illness than those that sample from the streets, or beyond the service system (Hopper et al. 2008; Smith and Castañeda-Tinoco 2019; Snow and Anderson 1993). The broad range of findings draws attention to how the methods used can often predetermine the results.

Street samples attempt to collect more data on street dwelling homeless individuals and what Rossi et al. (1987) called the "marginally or precariously housed" among hotels and those who double up with friends and family (Smith and Castañeda-Tinoco 2019). Examples of the hidden homeless or marginally housed homeless include those who stay on a friend's or family member's couch, rotate staying with various friends or family, or someone who stays in a hotel/motel one night but may sleep outside the next-and visa-versa. The marginally housed are especially challenging to survey or count due to their absence in traditionally recognized homeless spaces, which makes calculating those with mental illnesses especially complicated.

Problems go beyond operationalizing who is "homeless," and defining "mental illness." In a review devoted to measuring mental illness among those experiencing homelessness during the 1980s, Susser et al. (1990) cite common problems, such as (1) sampling issues (especially sampling homeless outside shelter populations), (2) delineating the measurement of incidence of homelessness versus prevalence of homelessness, (3) getting diagnosed by a lay volunteer rather than a qualified diagnostician, and (4) defining reports of general "distress" as symptoms. They go on to say:

Uncertainty pervades ... Reported diagnoses and assessments by means of scales are fraught with problems of interpretation. There is no measure that is comparable across all or even most surveys ... At this time it is essential to identify the sources of error and the limits to our knowledge, for the field to advance (Susser et al. 1990, p. 410).

Considering how difficult prior research found measuring mental illness among homeless individuals, it is problematic to assert that a supposed majority of the people experiencing homelessness are in fact mentally ill, or more mentally ill than those who are not experiencing homelessness. More importantly, it is problematic that many of those experiencing homelessness who are not mentally ill "enough" cannot access housing services.

Problems persist despite the slew of scholarly calls for policy reevaluation. Many ethnographers find that people experiencing homelessness are forced to participate in a medicalized context when they interact with service providers. It is important to consider how social contexts of being without a home might lead to coping strategies that are rational survival strategies, a point emphasized by Snow et al. (2014) in their paper On the Precariousness of Measuring Insanity in Insane Contexts. After all, people are not mentally ill just because they are not living in a home. For this reason, they argue that researchers should be aware of mistakenly interpreting their homeless respondents as dysfunctional when it could just be their adaptation to the social context of being homeless, which is not a "normal" situation (Snow et al. 2014).

\subsection{Lingering Medicalized Structure}

Since the 1990s, cities receiving federal funding from HUD have used a tiered model consisting of emergency shelters, transitional housing, and permanent housing, commonly referred to as the "Continuum of Care" (CoC) (Gowan 2010; Wong et al. 2006), and the 2009 Homeless Emergency Assistance and Rapid Transition to Housing (HEARTH) Act formally mandated it (Perl 2017). The CoC consists of three phases to help people experiencing homelessness through the housing process: phase one is emergency shelters, phase two is transitional shelters, and phase three is permanent housing (Gowan 2010). Emergency shelters can be overwhelmed with hundreds of people who complain of little sleep due to noise during the night, risk of theft, and drug activity in the restrooms, and all this can prompt inhabitants to reconsider how rational it is to stay there (Wasserman and Clair 2010). Then, 
homeless individuals must be processed and be accepted into case managers' already overburdened caseload to access housing services via transitional housing or permanent housing (Ranasinghe 2017).

Shelter Plus Care previously targeted those experiencing homelessness who were SMI, had verifiable addiction, or had HIV/AIDS. The HEARTH Act has since identified CoC funding to be exclusively for those who fit the definition of "chronic" homeless (i.e., those who have documentation of a formal disability and have experienced homelessness for over one year or four times in three years). CoC funding represents $88 \%$ of all Homeless Assistance Grants (Perl 2017, p. 30). While some researchers focus on HUD's mandate to fit time criteria of "chronic" homelessness (Smith and Anderson 2018), all homeless individuals seeking housing via CoC must have a formal disability that is interpreted by diagnostician or clinical social workers to be severe enough for admission into housing—not just any mental illness will do.

Limited funding compounds the issue of housing the homeless. In the United States, each city has varying levels and types of local, county, and state funding availability that supplement its federal funding. However, there are only a handful of local municipalities that supplement funding beyond what HUD provides (Padgett et al. 2016). Additionally, the 2009 American Recovery and Reinvestment Act (ARRA) staved off mass homelessness following the Great Recession of 2008 by briefly supplying Homelessness Prevention and Rapid Re-Housing Program (HPRP) funding across the U.S.- - bolstering "Housing First" initiatives. Despite its successes, all HPRP funding ceased in September of 2012 (HUD 2019). Unless cities continue to provide external funding, social service workers, and the people they work with must participate in the current medicalized $\mathrm{CoC}$ model in order to navigate successfully into housing.

Under current policy, written documentation includes a formal diagnosis of SMI, among other qualifying vulnerabilities. For example, common preliminary conditions for formal access into these programs state:

Individuals were eligible to receive housing at either residence if they were living on the street or in a shelter and had at least two of the following disabilities: substance use disorder, mental illness (axis I or axis II diagnosis), and HIV-AIDS. To qualify for residence in the Lyric, one of the disabilities had to be a diagnosis of an axis I mental illness. A small proportion of Canon Kip units (nine units, or 9\%) were allocated to individuals with only one diagnosis. A clinician confirmed all diagnoses in writing, and a social worker certified homeless status (Martinez and Burt 2006, p. 993).

Considering formal diagnoses must be in writing, only a handful of researchers have focused on how homeless individuals interact with service providers in this regard. Theresa Gowan's ethnographic research found, among three general types, that those experiencing homelessness often speak in terms of "sick-talk" while interacting with service providers and researchers. By this, she means that some homeless individuals speak of mental illness and other medical conditions that may qualify them for services even when unprompted. It is still unclear if sick-talk exists due to perceived desired responses that respondents think may help them access housing.

Additionally, Lyon-Callo (2000) found it standard practice for social service workers to medicalize the framing of homeless clients in their advocacy for homeless services, beginning the moment they walk through the service door for intake. If homeless individuals are unwilling to conform their identity to the existing medicalized purview, it can result in the stigmatized official label of "non-compliant" among service providers and result in being discharged from services altogether (Lyon-Callo 2000). In other words, it might be their reluctance to conform to a medicalized shelter system that leaves people sleeping on the streets. Medicalized systems occur in both $\mathrm{CoC}$ models and Housing First models (Osborne 2018). The previous literature questions how those experiencing homelessness adapt their interaction with both service workers and researchers following the lingering assumption, or desired response, that affirmatively identifying as mentally ill (among other illnesses) may be necessary in exchange for housing entry. This is especially true if they are not otherwise verifiably "disabled" under current policy. 


\subsection{Comparison to the Domiciled Population}

Historically, defining mental illness among those experiencing homelessness has been problematic, yet these assumptions are contextualized when compared to mental illness among the housed population. The Substance Abuse and Mental Health Services Administration (SAMSHA) uses the National Survey on Drug Use and Health (NSDUH) to distinguish serious mental illness (SMI) from any mental illness (AMI) in their study of domiciled populations. The NSDUH measure mental illness of the domiciled (housed) population and provide a more specific determination of the severity of mental illness among homeless individuals than has been previously utilized. The NSDUH consistently found that the prevalence of any mental illness (AMI) among the general population in the U.S. over the past ten years to range from $17.7-19.1 \%$, and serious mental illness (SMI) to range from 3.7-4.6\% (SAMHSA 2020).

\section{Methods}

We conducted a Point-in-Time (PIT) study using a modified version of HUD's official PIT survey in El Paso, TX. While HUD's PIT is perhaps the best and most referenced public data gathering on homelessness, there are extensive problems with its methodology (NLCHP 2017; Smith and Castañeda-Tinoco 2019). Despite HUD's PIT limitations, we have two reasons to do this. First, we focused on street populations and not solely those from institutionalized settings. Second, PIT aggregates are the most widely used database to inform public policy (HUD 2019; Jackson 2007). We enacted a few moderate improvements, as we describe in this section and elaborate in the limitations section.

\subsection{Replication}

HUD currently conducts a mandated annual homeless Point-in-Time (PIT) to count the total homeless population in every major city across the United States. The information gathered in HUD's PIT count is reported to the U.S. Congress (HUD 2007-2018 2019; Jackson 2007) and the U.S. Census Bureau for population estimates and public policy development concerning homeless services, poverty, and urban planning. Although the methods of HUD's PIT counts have been heavily critiqued (NLCHP 2017), it is the most utilized quantitative data available on homelessness.

Most major cities conduct two separate counts as part of their annual HUD PIT count. The first part counts those within the service industry, such as at shelters, soup kitchens, and halfway houses, while the second part is a "street count" to account for those experiencing homelessness not accessing shelter services.

The first author worked as a social service worker from 2002-2008 and participated in HUD PIT counts since 2002 in Cincinnati, OH, Covington, KY, Phoenix, AZ, and El Paso, TX. The street count is typically conducted using volunteers from the local community who receive limited training, usually an hour. Homeless subpopulations that do not fit traditional stereotypes have been difficult to study, specifically immigrants, people sleeping in automobiles, or those temporarily living with friends or extended family. These groups are hidden populations that are often difficult to sample (Rossi et al. 1987; Smith and Castañeda-Tinoco 2019).

The National Coalition for the Homeless (2013) acknowledges the caveat that "Point-in-time count methodologies vary and are imperfect and as such the aggregated numbers do not represent a precise count of homeless people" (5). Thus, any percentages of subpopulations should be aggregated with similar caution. Controversy over the operationalization of terms has also compounded problems with HUD's count. This includes periodic changes in defining such terms as "homeless," "chronic homelessness," and "mental illness." The 2009 HEARTH act renewed and restructured the McKinney-Vento Homeless Assistance Act initially passed in 1987 and finally defined homelessness as "one without adequate place to sleep at night" (HEARTH 2015). The official HUD PIT survey also measures mental illness with only one question by asking, "Do you think you have any current 
psychiatric or emotional problems?" Despite this question being widely used across the U.S. (HUD 2018), it is problematic for several reasons, including that simply saying "yes" does not technically qualify as having a diagnosed mental illness. Furthermore, such responses grant no certainty to the severity of the symptoms or accessibility into services. Most people conducting PIT counts are not mental health professionals and cannot make clinical assessments themselves.

\subsection{Our PIT}

We conducted a Point-in-Time (PIT) Replication Study in El Paso, TX, using a modified version of the HUD's official PIT survey used to count the homeless population. Our study focused specifically on delineating varying types and severity of mental illness among the homeless population. It consisted of the same survey questions as El Paso's official HUD PIT street count conducted on 24 January 2013, with the addition of three follow-up questions concerning mental health/illness (The survey instrument we used is published in Smith and Castañeda-Tinoco 2019).

We conducted the PIT replication study between 4:00 a.m. and 10:00 p.m. on 27 February 2013. Respondents were included if they reported being homeless according to HUD's "chronic" homeless definition or stayed the previous night in an "inadequate place to live" according to the 2009 HEARTH Act, which also includes Rossi et al.'s (1987) "marginally housed" populations. We focus on those who reported that they had mental health concerns or reported symptoms or diagnoses of mental illness. All reported symptoms of mental illness, even potential mental illness, were included and counted as any mental illness (AMI).

The project received IRB approval from the University of Texas at El Paso where the class was taught as part of a larger study (see Loza et al. 2017), whose protocols were reviewed by an interdisciplinary group of scholars at the Hispanic Health Disparities Research Center and approved by program officers at the National Institute on Minority Health and Health Disparities at the U.S. National Institutes of Health (NIH). This replication count was a possible research project for undergraduate students enrolled in Castañeda's "Methods of Research" class. Students were trained in proper research techniques for weeks, including on how to conduct surveys and interviews efficiently and ethically before conducting the survey, and were given clear direction on what to do in risky situations and had direct oversight (class syllabus is supplemental material published in (Smith and Castañeda-Tinoco 2019)). All participants received human subjects training and took the test to be certified to protect human research participants by the NIH. Students often worked in pairs, and small teams were aided by graduate students, including Curtis Smith and Josue Lachica, both of whom had ample experience working with homeless individuals as outreach workers.

As in other point-in-time censuses, the goal was to survey and count every single homeless person possible. Students had designated areas within the city to survey the homeless population. Surveyors did not enter any homeless service centers and wrote a short description of what the homeless respondents wore so that any duplication of surveyed respondents could be tracked and eliminated during data analysis. With the same objective, we had respondents name the city and street where they grew up.

We describe the success of the study in a previous publication (Smith and Castañeda-Tinoco 2019) in finding hundreds more homeless individuals than the official PIT count that year. A paper comparing homeless situations along ethnic lines (Castañeda et al. 2014) has been used as a textbook case study on how to study health disparities among minority vulnerable populations (Frankfort-Nachmias and Leon-Guerrero 2017, pp. 239-43).

We added the following three fill-in-the-blank questions to the PIT survey carried out one month prior by the local coalition for the homeless: "Have you ever been formally diagnosed with a mental disorder?" "If so, by whom?" And then, "What symptoms do you experience that concern you?" The answers to these questions were recorded in the database exactly as respondents answered them. We recorded all responses of self-reported mental illnesses and symptoms of potential mental illnesses. Since the first author had a history of employment by mental health organizations 
and had received training to assess homeless people for potential mental illness, he categorized all responses according to the Diagnostic and Statistical Manual of Mental Disorders (DSM-IV) (American Psychiatric Association 2000).

All "yes" responses to the official question were included. Respondents concerned with their mental health were measured according to diagnoses, or by their reported criteria of symptoms of possible mental illness according to the DSM-IV. Symptoms were obtained in the open-ended text responses were then categorized by potential diagnoses. We included answers to "what kind of symptoms?" referencing mental health in general, and any responses referencing symptoms of SMI were classified as such in a new variable. This is a substantial improvement from the official PIT survey for El Paso, which asked, "Do you think that you have any current psychiatric or emotional problem(s)?" For example, identifying as "unhappy" could be characterized by depression by some, "paranoia," or seeing things others do not see could be "schizophrenia," or a combination of "happy" and "paranoia" were coded as possible, undiagnosed, "schizoaffective disorder." We also recorded if participants were diagnosed or undiagnosed. If respondents indicated that they had been diagnosed by someone who was not a clinician, surveyors marked that the respondents answered "myself," and then were considered "undiagnosed" in the data. To avoid undercounts and underestimating, "undiagnosed" was aggregated to "diagnosed" to represent total populations with possible mental illnesses. Therefore, our mental health prevalence is on the generous side and possibly overcounts actual cases.

\subsection{SMI and AMI}

We apply NSDUH's terms, "SMI" and "AMI," to assess how many could access housing programs. The NSDUH says:

Respondents were defined as having any mental illness (AMI) if they were determined to have any of the mental disorders ... regardless of the level of functional impairment ... Respondents were defined as having serious mental illness (SMI) if they had any of the mental disorders ... result[ing] in substantial impairment in carrying out major life activities ... The SCID and the GAF in combination were considered to be the "gold standard" for measuring mental illness (pp. 65-66).

Considering how the domiciled (housed) populations are measured according to severity is relevant to homelessness because only those with formal diagnoses considered severe enough are accepted into housing.

We used the terms of any mental illness "AMI" and serious mental illness "SMI" as utilized by SAMSHA's NSDUH. First, we focused on those who answered "yes" to the question, "Do you think you have any current psychiatric or emotional problems?" or provided any affirmative answers to the subsequent questions on mental illness. Those cases were separated into a variable and coded as "AMI." The official question is framed to capture their current condition. However, we also instructed surveyors to mark any mental illness in their history (i.e., prior hospitalization or diagnoses). AMI represents an aggregated total of anyone who reported any symptom or diagnosis of mental illness.

We realize that it is not feasible for HUD to use traditional assessments utilized for the severity of mental illness, such as the Level of Care Utilization System (LOCUS) because administering these assessments would be too time-consuming as each assessment takes over an hour (LOCUS 2020). To streamline this process, we asked open-ended questions that could then be categorized. We recorded all respondents who said they either had (a) a formal diagnosis or, (b) symptoms of mental illness, following the DSM-IV, on any part of the survey, and categorized them as "diagnosed" or "undiagnosed." We needed to categorize these reported diagnoses along with any symptoms of possible serious mental illness to create a category for "SMI." Jans et al. (2004) list of SMI disorders include:

... diagnoses of schizophrenia, schizoaffective disorder, manic-depressive disorder, autism, severe forms of major depression, panic disorder, or obsessive-compulsive disorder, because 
these disorders are so severe that they almost always lead to serious impairment if not treated (p. 55).

Using this list of disorders in Jans et al. (2004) and the DSM's descriptions of SMI, we categorized reported symptoms into the corresponding mental illness. For example, if the respondent indicated any sort of depression, then the surveyor asked for the duration of depression. If the symptoms of mental illness responses were anything that had lasted over twelve months, then they were coded as "dysthymia" and categorized as SMI. Cases that were not considered SMI but were still "mentally ill" were left in the AMI category.

We also coded these cases in a separate variable called "undiagnosed" and "SMI" if respondents reported symptoms of conditions listed in Jans et al. (2004). We assumed that they could be diagnosed if they had access to a formal diagnostician, so we recorded any indication of mental illness in our analysis. The two numbers of "diagnosed" SMI and "undiagnosed" SMI were added together for a total population of SMI.

All cases that reported symptoms of possible mental illness were added to cases that were diagnosed, SMI, or AMI, respectively. If clarification was needed, we followed-up with surveyors or physical surveys during the coding process to ensure accuracy. In short, if respondents reported a mental illness diagnosis on Jans et al. (2004) list of SMI disorders, then they were coded as SMI, and categorized as "diagnosed." We also included those who reported being institutionalized/hospitalized for their mental illness as "diagnosed" and "SMI."

Similar to SAMSHA and NSDUH, conditions not severe enough were left in the AMI category. However, SMI is technically included in the AMI category. Therefore, to make these categories mutually exclusive for comparison, we created another category called other mental illness (OMI) for those cases unambiguously not severe (SMI). OMI cases were any respondents who described mental health concerns, symptoms, or diagnoses of mood disorders and disorders such as Attention-Deficit/Hyperactivity Disorder. These disorders are not as severe. Like SMI, we aggregated OMI according to "diagnosed" and "undiagnosed" to get a total population of OMI.

AMI comprised an aggregated total of SMI and OMI (including diagnosed and undiagnosed). After the categories of AMI and SMI were separated along with "diagnosed" and "undiagnosed," the comparison could be made with the non-homeless. OMI homeless cases theoretically struggle to fit categories seen as vulnerable enough for housing access, according to funding sources for housing and homeless assessments, such as the Service Prioritization Decision Assistance Tool (SPDAT 2020). When finished with this step, we delineated cases with reports of any indication of mental illness according to the following categories: SMI, AMI, diagnosed, or undiagnosed.

Included in the standard HUD PIT survey was the question, "What type of services did you really need but you could not get in the last 12 months?" A possible answer to this question was "Mental health services." Additionally, if a respondent felt that they might be experiencing mental illness, surveyors were instructed to offer an on-site, good-faith mental health assessment by an expert and provide transportation to a formal diagnostician for proper assessment. No respondent asked for this type of help. We also provided service referrals, and all surveyors had the cellphone numbers of nurses and social workers ready to meet individuals who requested it on the spot.

\section{Findings}

Our survey was applied to a total of 678 homeless individuals who were found through network sampling or under bridges, at local parks, or otherwise on the streets, although $24 \%$ of respondents said they had slept in a shelter the night before being surveyed. Given that we counted respondents who provided any indication of mental illness, however severe, we found $19.8 \%$ answered "yes" to the official question, "Do you think that you have any current psychiatric or emotional problem(s)?" Seven cases described any mental illness conditions or symptoms in subsequent responses, which brought the total AMI population to 20.8\% (see Figure 1). Among the AMI population, $4.3 \%$ were diagnosed SMI, and 1.9\% showed symptoms of SMI (including undiagnosed who described only 
symptoms). When aggregated together, we found the total population for SMI to be $6.2 \%$. When we subtract the total SMI population from the total AMI population, we are left with 13.6\%. Other Mental Illness (OMI) are those who reported symptoms of mental illness according to the DSM-IV but did not report SMI diagnoses or symptoms of potential SMI. Of the total population of $678,10 \%$ provided symptoms that included mood disorders, such as emotional, insomnia, sadness, or otherwise situational conditions. The OMI population is that which prior research on the subject typically includes in their findings on general mental illness. However, the current definition of "chronic" homelessness does not consider that these cases are severe enough to qualify for housing services. In short, 14.6\% (OMI) of the mentally ill homeless do not report symptoms that are severe enough to access current housing that prioritizes only the chronic homeless.

Additionally, some affirmative responses to the official question ("Do you think that you have any current psychiatric or emotional problem(s)?") responded to our original follow-up survey questions with answers such as "foot aches," "non-mental health condition," "economics," or other non-mental concerns, and three cases were concerns about addiction despite addiction already being recorded in another variable. These cases were removed from the mental illness category.

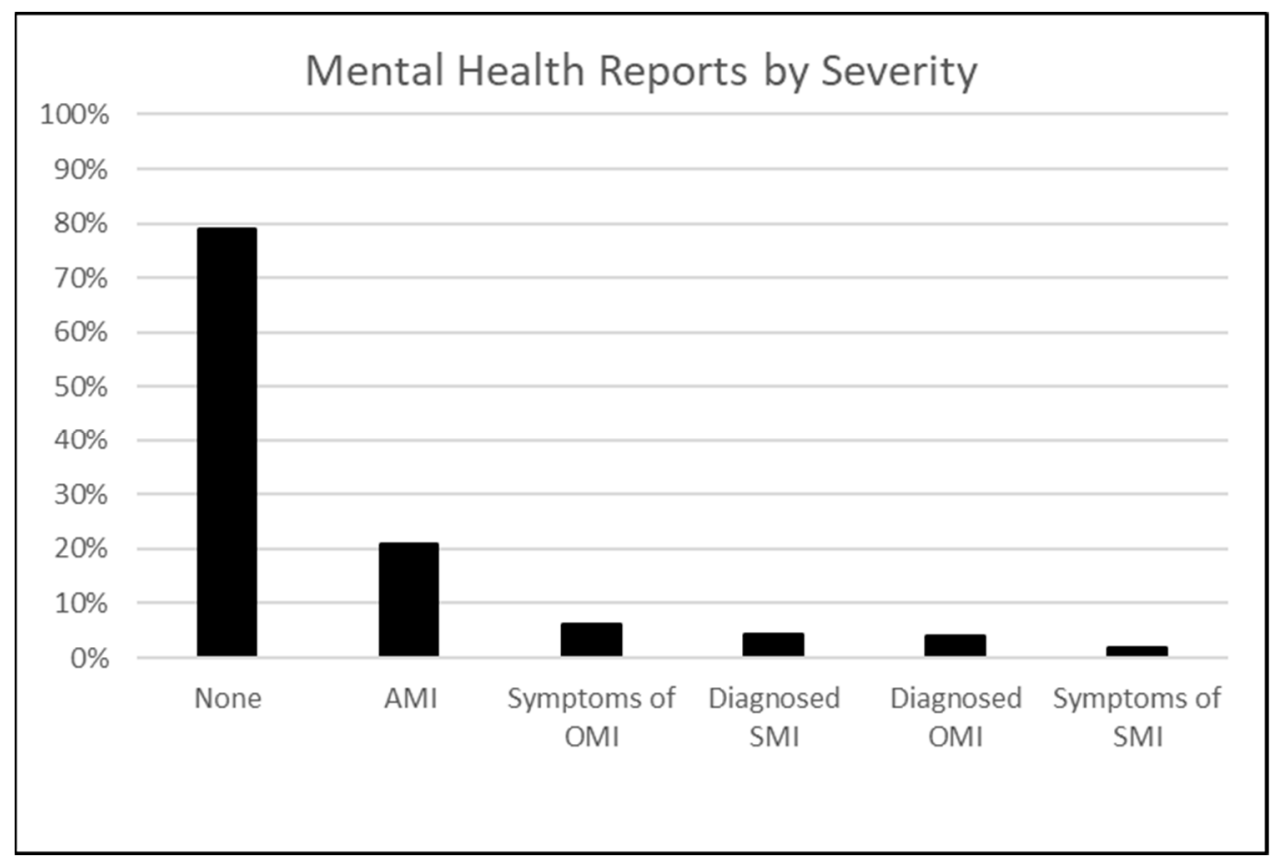

Figure 1. By Authors. AMI = Any Mental Illness; SMI = Serious Mental Illness; OMI = Other Mental Illness (AMI but not SMI).

When asked, "What type of services did you really need but you could not get in the last 12 months?" 6.3\% reported needing "mental health care" (see Figure 2). When only considering those who desired "mental health care" services, most were those who were diagnosed (Diagnosed SMI or Diagnosed OMI) or previously had experience with mental health services. For this question, OMI was split between "diagnosed" and "undiagnosed" at 13.9\%. Those with symptoms of SMI (undiagnosed) and desired services were the least at $11.1 \%$ (see Figure 2). Only 27.8\% of this group reported an SMI diagnosis, and another $11.1 \%$ exhibited symptoms of SMI (see Figure 2). Interestingly, the largest number of those who desired services but could not access (33.3\%) was among those who marked "no" for the official question regarding mental concerns. Thus, one-third of those who desire to qualify for mental health services do not report a mental health concern, which could mean they either underreport mental health concerns or simply wish they could qualify for services they know they do not currently qualify for. If homeless individuals do not have mental health concerns but desire services in any form, this should be considered for policy implications and is discussed below. 
Additionally, 75\% of the total sample fit the time criteria of being "chronically" homeless by having been homeless for over one year or four times in three years. Most of these cases did not have an accompanying disability.

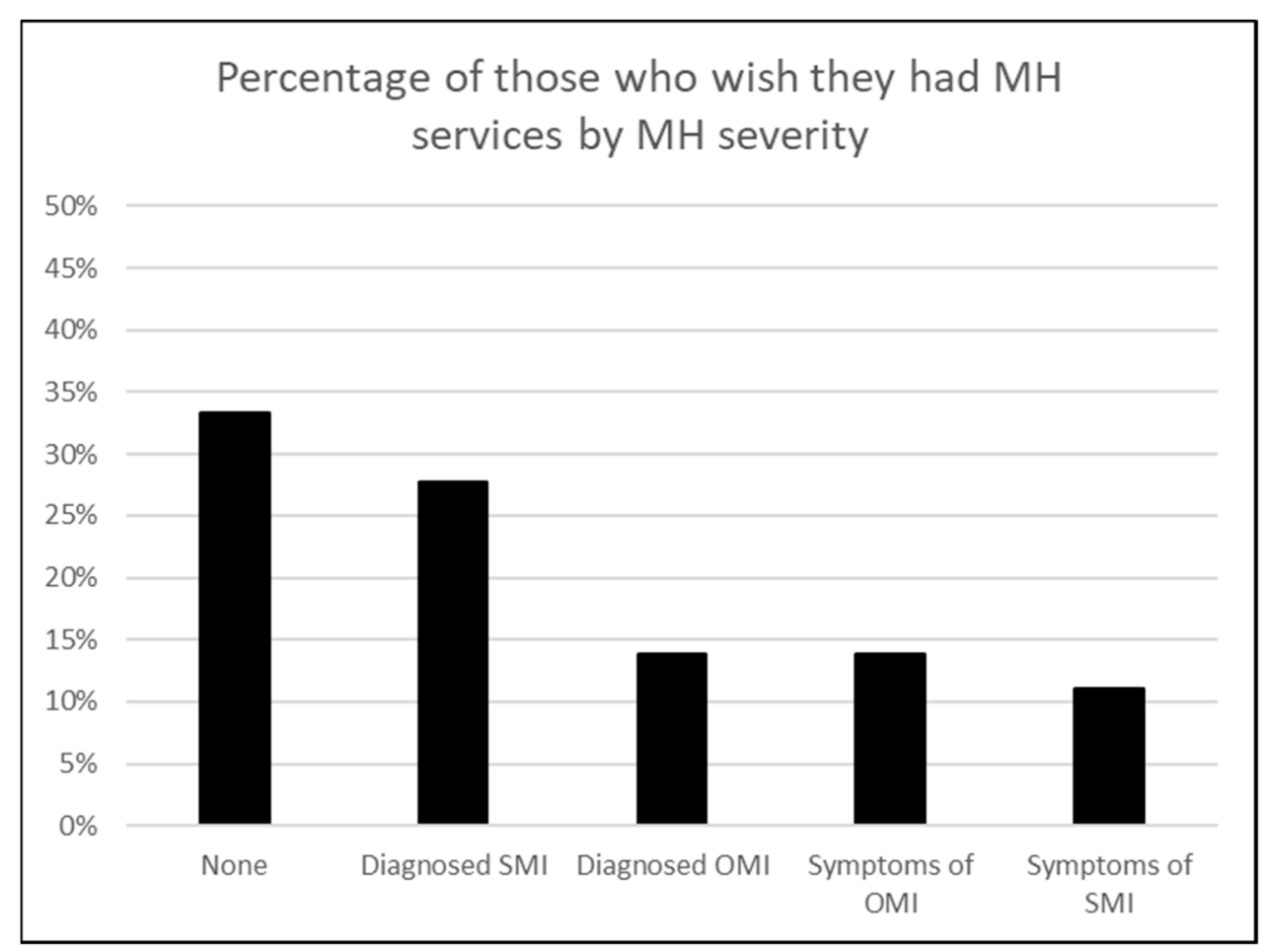

Figure 2. By Authors.

\section{Discussion}

Snow et al. (1986) explain in their article The Myth of Pervasive Mental Illness among the Homeless three reasons for the medicalization of the homeless: the medical profession defines the scope of the problem and granted expertise, the problem is framed from the standpoint of the medical model, and that the medicalized perspective functions as the only way the problem is viewed and debated publicly. They conclude saying,

Additionally, attention has been focused primarily on "flaws" and "impediments" within homeless individuals and the mental health system, rather than on the larger social structure. As a consequence, socioeconomic factors-such as the lack of jobs with decent pay, dislocations in the job market, and decline in the availability of low-income housing-tend to be ignored or discounted as the major causes of homelessness. The general result is that the prevalence of mental illness among the homeless is exaggerated and the stereotypic image of the homeless as men. (Snow et al. 1986, p. 420)

Our findings for this sample in El Paso, also show that the actual majority of the homeless are not mentally ill despite popular belief. Further research in El Paso and other cities should test whether this is the case elsewhere.

Our findings support the medicalization hypothesis over the deinstitutionalization argument. In other words, our findings support the argument that homelessness has been individualized and medicalized in ways that defund universal services and prevent many who are poor from receiving aid. By asking respondents to clarify what their mental health concerns were, we produced findings very close to other homelessness studies that sampled street homeless instead of sheltered homeless (see Figure 3). Our 20.8\% total of homeless respondents with any mental illness (AMI) is consistent 
with most available research on the subject that samples street homeless (see Figure 3). We found only $6.2 \%$ SMI, which is surprisingly similar to the housed population in the U.S. at 3.7-4.6\%.

We see that mental illness in general (AMI) — and much less SMI—is not disproportionally common among the homeless, something that is often claimed by laypersons, some social service workers, and research that limits sampling to shelters (or otherwise institutionalized settings) where formal disability is often a prerequisite for admission. While our findings are comparable to prior research focusing on mental illness more generally (HUD 2013; Shlay and Rossi 1992; Snow and Anderson 1993; Susser et al. 1990), our study stands out because we specify the severity and compare to the general population. We recognize the uniqueness of our census in comparison to other studies on the subject because we sampled the streets and included respondents who reported sleeping in the streets and shelters as well as the marginally housed population sleeping in cars or "couch surfing" to capture the full diversity of the homeless population, which is beyond the traditional sampling of people experiencing homeless spells. The comparison and resemblance to the housed population should not be too surprising since many individuals experience homeless spells but are not homeless long-term. There can be a revolving door between renting, being evicted, working while homeless, and getting back into housing (Jencks 1994; Rossi 1991).

Susser et al. (1990) stated that "Uncertainty pervades existing survey data on the frequency of mental illness among the homeless ... no measure that (sic) is comparable across all or even most surveys (p. 410)." Studies still use varying methods and motives for studying the subject, which we feel calls into question who is creating and using the assessments meant to study it. We feel we have furthered the knowledge on the subject, based on who is sampled.

Our findings are consistent with prior studies that reflect lower rates among street samples in comparison to higher mental illness rates among the sheltered, or otherwise institutionalized, samples. Shlay and Rossi's (1992) meta-analysis of 60 studies on those experiencing homelessness found that $33 \%$ of homeless individuals have a current mental illness with a significant standard deviation of 23 and a range of other findings on mental illness from $4-100 \%$. They also acknowledged a considerable variation in prior research, saying that they can often focus attention on stereotypical subpopulations of homeless people who stay in specified types of shelters neglecting other populations. Additionally, Snow and Anderson (1993) focused on the prevalence of mental illness. The study surveyed 800 homeless individuals in Austin, TX, within service centers, and on the streets. Careful not to overlook any hidden mentally ill populations, the results of their study included anyone who could possibly be mentally ill, even if respondents that had not been formally assessed, or if reports were coming from third-party homeless people. Evidence of possible SMI was found to be at $9 \%$ of homeless respondents, with a follow-up study that found 16\% SMI (Snow and Anderson 1993). In our study, only 6.2\% described symptoms of SMI or were diagnosed SMI, so we can conclude that only $6.2 \%$ of the total population could qualify for housing services under $\mathrm{CoC}$ subsidized housing services due to their mental illness alone (assuming they have no other disability). HUD's PIT consistently reports around one-third of the homeless population to be mentally ill over the past ten years (HUD 2007-2018 2019).

\subsection{Compared to the Non-Homeless Population}

Our findings are also similar to studies that measure mental illness among the general U.S. population. The NSDUH reports the prevalence of AMI from 2008-2018 to range between 17.7-19.1\% and SMI 3.7-4.6\% (SAMHSA 2020). Studies such as Kessler et al. (2005) also indicate mental illness among the general population in the U.S. to be as high as 23\% SMI, but do not include AMI in their findings. These surveys are unlikely to include respondents who were homeless at the time of the survey. 


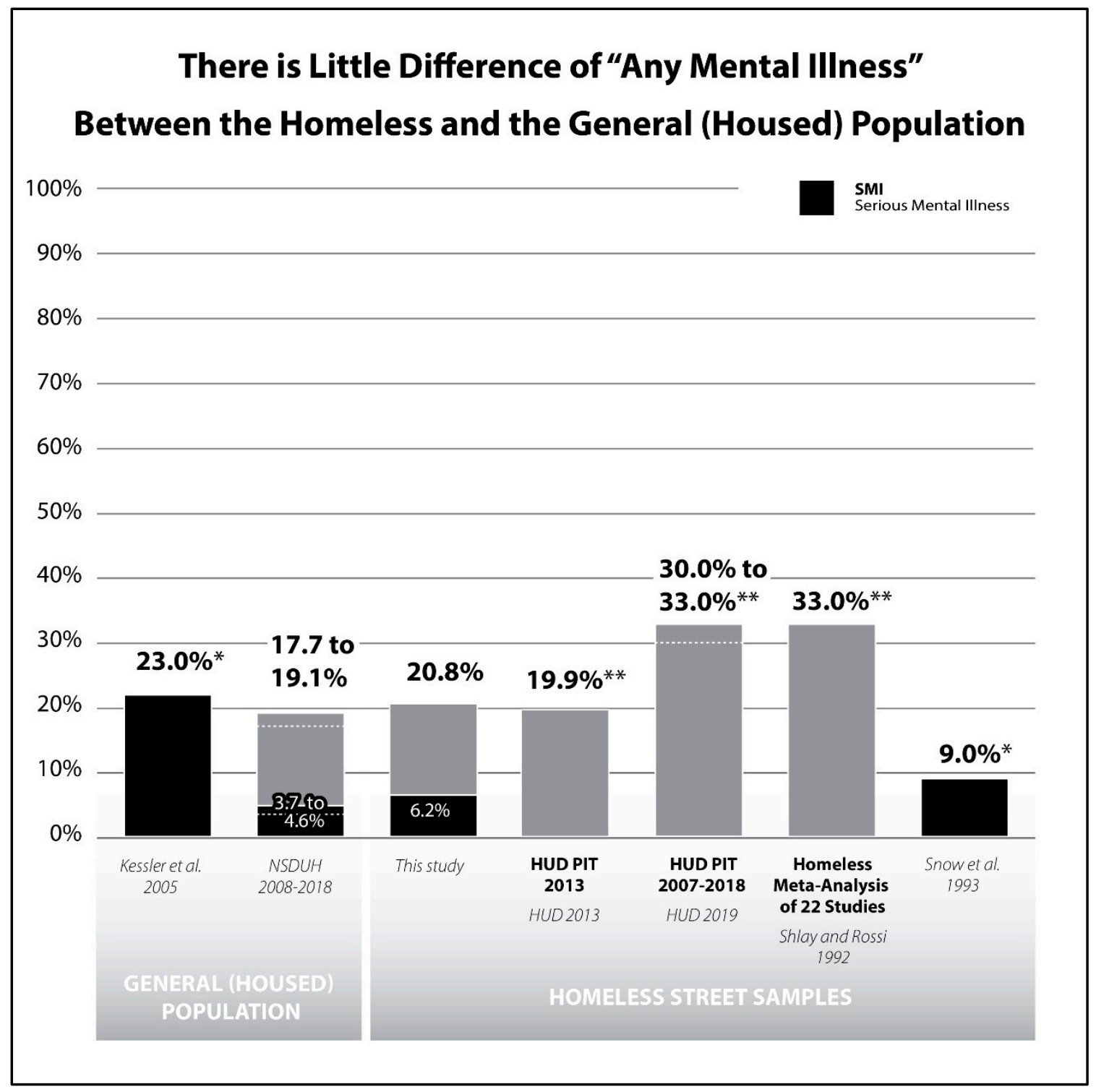

Figure 3. Comparison across studies, including HUD (2013), HUD 2007-2018 (2019), Kessler et al. (2005), NSDUH (2018), Snow and Anderson (1993), and Shlay and Rossi's meta-analysis (1992). Studies that sample only sheltered or otherwise institutionalized homeless are omitted. * Studied only SMI; ** Studied any mental illness (did not specify SMI).

Additionally, HUD's annual PIT is the top referenced quantitative information used to develop policy. Figure 3 illustrates how HUD's PIT national aggregates consistently found 30-33\% mental illness for over a decade (HUD 2013; HUD 2007-2018 2019). To our knowledge, the studies in Figure 3 include all available literature on the subject in the past 50 years that sample homeless populations outside of institutionalized settings.

Figure 4 shows a cross-tabulation of the distribution of all those who reported symptoms or diagnoses of mental illness, by where they stayed the night before the day they were surveyed. As suspected, those who reported diagnoses of SMI at a higher rate stayed in the shelter system at $11.2 \%(2.6 \%+8.6 \%)$ compared to $5.1 \%$ who stayed on the street or unspecified, and $5.3 \%$ among the marginally housed. Those who reported OMI symptoms or diagnoses totaled $10 \%$ in shelter compared to $9.3 \%$ on the streets or unspecified, and $14 \%$ among the marginally housed. 


\begin{tabular}{|c|c|c|c|c|c|c|c|}
\hline \multicolumn{8}{|c|}{ Where do People with Mental IIIness Stay? } \\
\hline & & \multirow[b]{2}{*}{ None } & \multicolumn{2}{|c|}{ OMI } & \multicolumn{2}{|c|}{ SMI } & \multirow[b]{2}{*}{ Total } \\
\hline & & & $\begin{array}{c}\text { Only } \\
\text { Symptoms }\end{array}$ & Diagnosed & $\begin{array}{c}\text { Only } \\
\text { Symptoms }\end{array}$ & Diagnosed & \\
\hline \multirow{6}{*}{$\begin{array}{l}\text { Housing by } \\
\text { category }\end{array}$} & \multirow{2}{*}{ Sheltered } & 119 & 9 & 6 & 4 & 13 & 151 \\
\hline & & $78.8 \%$ & $6.0 \%$ & $4.0 \%$ & $2.6 \%$ & $8.6 \%$ & $100 \%$ \\
\hline & \multirow{2}{*}{$\begin{array}{l}\text { Street or } \\
\text { Unspecified }\end{array}$} & 284 & 18 & 13 & 7 & 10 & 332 \\
\hline & & $85.5 \%$ & $5.4 \%$ & $3.9 \%$ & $2.1 \%$ & $3.0 \%$ & $100 \%$ \\
\hline & \multirow{2}{*}{$\begin{array}{l}\text { Marginally } \\
\text { Housed }\end{array}$} & 121 & 13 & 8 & 2 & 6 & 150 \\
\hline & & $80.7 \%$ & $8.7 \%$ & $5.3 \%$ & $1.3 \%$ & $4.0 \%$ & $100 \%$ \\
\hline \multirow{2}{*}{ Total } & & 529 & 41 & 27 & 13 & 29 & 633 \\
\hline & & $82.8 \%$ & $6.4 \%$ & $4.2 \%$ & $2.0 \%$ & $4.5 \%$ & $100 \%$ \\
\hline
\end{tabular}

Figure 4. By Authors. SMI = Serious Mental Illness; $\mathrm{OMI}=$ Other Mental Illness.

It is common for some prior research to assert that it is concerning that one-fifth to one-third of the homeless population shows signs of mental illness. Instead, we argue that it is not concerningly high compared to the general population. In the case of this study, the narrative goes beyond asserting that one-fifth of the population is mentally ill. We demonstrate that AMI is similar to the domiciled (non-homeless) population. We also show that SMI among those experiencing homelessness is only a fraction of AMI and that it is very similar to the domiciled population. This SMI category is the only population eligible for CoC housing under the current policy. We want to emphasize that with the blank space in Figure 3 that the actual majority of homeless are not mentally ill, which is consistent with other studies in recent decades that sample beyond sheltered or otherwise institutionalized homeless. If we want to help homeless people, it is not only through mental health services but through housing assistance to those in economic need.

\subsection{Research Implications}

It is concerning that the most widely used survey, HUD's PIT, only uses one question in their annual survey to measure mental illness among the homeless population: "Do you think that you have any current psychiatric or emotional problems?" We are aware that different cities may have another version of the official survey, but most cities only use HUD's official questions. Responses from our additional questions provided substantial additional information. We also are not alone in advocating that HUD improve the official PIT count (NLCHP 2017). Recently HUD's question has been changed to, "Do you have psychiatric or emotional conditions such as depression or schizophrenia?" (HUD n.d.).

Research such as Shlay and Rossi (1992) meta-analysis of over 60 studies adds that "Wide variation in estimates of the prevalence of mental illness are shown because there is neither a universally accepted definition of mental illness nor a common method for measuring mental illness" (Shlay and Rossi 1992, p. 137). However, to our knowledge, there has been no indication of distinguishing mental illness among the homeless by type. By including the marginally housed and categorizing mental illness by severity, our contribution clarifies how many homeless individuals report mental illness who qualify for housing services under the current definition of "chronic" homeless under current federal HUD policy. Despite continued support for increased availability of mental health services by advocacy groups and some prior research, we find fewer street homeless individuals who may report mental health concerns in official surveys actually exhibit or report the necessary clinical SMI conditions that could qualify them for such housing under HUD's official policy and limited funding allocations. That is, asserting high rates of mental illness among those experiencing homelessness that are already 
institutionalized is misleading mainly because policy already mandates that sheltered homeless be limited to the very subpopulations the research is trying to measure.

Despite popular belief, there is a clear trend among the literature that the actual majority of the homeless are not mentally ill, and even fewer are seriously mentally ill (SMI). It is time to rethink how homelessness is researched and reconsider social policies that cater to stereotypes on homelessness. Even substance abuse has been found to happen only after time spent experiencing homelessness $(66 \%)$ compared to before experiencing homeless (33\%) (Johnson and Chamberlain 2008). Likewise, future research should consider whether homeless populations develop mental illness before or after spending time on the streets.

We believe our claims on mental illness among homeless individuals may appear challenging to advocate for because researchers and policymakers alike fallaciously assume mental illness is high because of reports that only sample the institutionalized homeless. They assume that studies omit, or overlook, cases because they do not fully understand (a) street homeless populations, (b) details of official housing policy stipulations, or (c) the categories SAMSHA uses to measure the general population or their respective findings. However, our findings are supported by other studies on the subject. Additionally, most assessments only ask binary "Yes/No" questions. Thus, anyone experiencing homeless with an understanding of the medicalized model can conclude that saying yes hints of desired responses from homeless respondents to simply answer "yes" in hopes for a chance at housing. Gowan (2010, p. xxi) refers to this phenomenon of constructing an identity to explain a reason for their homelessness "sick talk." Research also shows that social service workers feel that they need to "fit" their clients into this system by doing similarly (Smith and Anderson 2018).

Further analysis of our data shows that respondents occasionally reported "hearing voices." Someone said people were "out to get them." However, in these particular cases, it seems that these responses were related to a real fear-threats by others actually existed-and were not a symptom of schizophrenia or paranoia. These cases were still recorded in our data, but more importantly, other researchers or HUD volunteers could misinterpret these few cases as mental illness due to brief interaction with respondents and the fact that HUD measures mental illness with only one official survey question. The process is not so simple when speaking with a diagnostician. While answers can often represent a single symptom of SMI on HUD's survey, actual diagnoses per assessment, such as the MINI assessment (Sheehan et al. 2006), indicate that more information needs to be observed by a clinical diagnostician before a formal diagnosis should be given. Diagnoses are also largely at the "clinician's judgment" (Sheehan et al. 2006, p. 20). So, some of these cases would be turned away by the housing bureaucracy.

Despite the many methodological difficulties in researching mental illness, which are accentuated when conducting research among homeless populations, it must be undertaken. Gowan (2010) notes the importance of not simply focusing on the actions of homeless individuals who seek services, but of considering the larger culture that surrounds homelessness, and advocate for a more critical perspective in understanding the mental illness phenomenon within it. Observing mental illness among those experiencing homelessness within the scope of social service agencies can neglect the notion that the participants operate within a system that is irrational by design (Huey et al. 2012), and that it may be more rational for certain homeless individuals to sleep outside instead of seeking shelter services (Wasserman and Clair 2010). These notions demonstrate the necessity of a systematic analysis rather than merely observing the actions of individuals (Gowan 2010; Snow et al. 1986).

We made measuring the homeless outside of what Willse (2015) calls the service "industry," a priority. Our decision to include street homeless and marginally housed populations might also explain why our findings on mental illness are different. We do find variations across groups, but the total among all groups is $20 \%$ who show signs of any mental illness (AMI). We argue that policy caters to the most visible and homeless individuals who exhibit uncommon behavior at the expense of the broader population. Research on the institutionalized homeless among the service industry is prioritized and reinforces existing policy, which we will explain further. 


\subsection{Policy Implications}

HUD currently prioritizes $88 \%$ of its funding for Homeless Assistance Grants to Continuum of Care funds, formerly called Shelter Plus Care (Perl 2017), which mandates that homeless clients present written documentation of disability along with the duration of time spent homeless under the official "chronic" definition (Homeless Assistance Reauthorization 2019). We also believe this is evidence of a medicalized model. SMI accompanied by written documentation of formal disability are the only mental illness cases that fall under the current "chronic" definition mandated by HUD after drastic budget reductions of the 1980s. Options are limited for those experiencing homelessness who enter housing services under HUD.

We argue that funding priority should be more inclusive to broader populations of those experiencing homelessness. We want to elaborate that we do not advocate cutting funds that benefit the mentally ill. Policymakers should consider more expansive funding, such as in the DC model (Bogard 2001).

Our findings also support the argument that social service workers may use medicalization to frame clients in exchange for service aid, which is in agreement with Lyon-Callo's findings (2000). They use strategies that continue to medicalize those experiencing homelessness under the current policy (Dordick 2002; Osborne 2018; Smith and Anderson 2018). They must cater to the federal definition of "chronic" homelessness, mandated by the HEARTH Act of 2009 (Homeless Assistance Reauthorization 2019). Research such as Smith and Anderson (2018) and Osborne (2018) reference social service workers using the Service Prioritization Decision Assistance Tool (SPDAT), a tool commonly utilized across the U.S., to sell the idea that their homeless clients deserve housing over other homeless people who are waiting. Mental illnesses, such as instances of situational depression and most mood disorders, are deemed not "severe" enough to access many housing services.

Based on the policy recommendations on the traditional $\mathrm{CoC}$ model above, we suggest the prioritization of Housing First policies. We make this argument with full recognition that the implementation of existing Housing First programs in the United States shows lingering medicalized frameworks (Osborne 2018), which should be researched, evaluated, and improved further.

\subsection{Limitations}

While the data used for this paper concerns only the border city of El Paso, TX, experiences in other cities lead us to think that this is also the case elsewhere. We also have cited studies conducted by others with supporting findings. Further research should verify whether the mentally ill are in the minority within the overall homeless population in most cities in the United States and other parts of the world.

Does the fact that we studied a border city make homelessness different from that in non-border cities? Given that El Paso borders directly with Mexico, we find a higher number of Hispanics among the homeless than in other cities (Castañeda 2019). Nonetheless, Hispanics are still underrepresented, given their share of the general population (Tan and Ryan 2001; Castañeda et al. 2014). There are a number of Hispanics and others who are foreign-born, yet the majority of respondents $(66.6 \%)$ are U.S.-born. Some homeless individuals may indeed have returned voluntarily or been deported to Mexico. We also have information that many individuals were not born in El Paso but in other parts of the United States. This internal migration may be partly due to weather (Siorda et al. 2014) and to the relative tolerance of the local population, and to the affordability or the area and the resources afforded to have a transborder life (Comar 2011; Campbell and Lachica 2013; Castañeda et al. 2015). Beyond those already cited, qualitative studies in the area further complete the description of the homeless experience and mental health stigma in border cities (Moya et al. 2017; Aviña Cerecer 2020).

Contrary to the stereotypes, El Paso is not more dangerous than other cities (Castañeda and Chiappetta 2020), and its residents are not more likely to use drugs (Loza et al. 2017). Mental health could indeed be related to drug use or a decrease in social network size (Wright et al. 2017; Golembiewski et al. 2017). However, this is something beyond the scope of this paper. 
Our methodological limitations fall in line with the many limitations of the official HUD PIT count (NLCHP 2017) with problems, such as (1) inconsistent methodologies across time and geographic location in the United States making trends uncertain, and (2) undercounting unsheltered adults and youth. However, we improved on other problems with the PIT that the NLCHP (2017) identify, such as (1) counting the unsheltered population, (2) counting kinds of homeless individuals that are not served by social service agencies, and (3) making sure to avoid counting the "supply [but] not demand" of the homeless utilization of services.

In attempts to broaden sampling to include those who are not institutionalized, we also included surveys from the marginally housed population, which could have lowered the number of mentally ill because they are not in the shelters or medicalized systems. Our study focused on street and marginally housed homeless individuals that were not as subject to the medicalized framing. Our numbers capture more of the homeless universe than is traditionally sampled on the subject. We also found $20 \%$ more people than the official count (Smith and Castañeda-Tinoco 2019), but we are still likely undercounting people who are sleeping on the streets or are marginally housed. If it were possible to capture all cases, then they would probably further decrease the percentage of SMI among housing insecure people. Again, we also contend that this study overestimates AMI and SMI because we included any indication of mental illness during their lifetime and were not skeptical of responses. Students did not diagnose; they collected all responses, which were then categorized by potential diagnoses. We categorized all symptoms under the assumption that they could be diagnosed to avoid producing low estimates. For this reason, we feel that we slightly overestimate the cases of mental illness, both SMI and AMI.

It is also possible that some respondents had a mental health concern, but since it was not severe enough to be SMI (or able to receive housing), respondents answered "No." This, in turn, would have had the effect of lowering the number of respondents reporting mental health "concern." Additionally, we understand that cases of mood disorders, such as depression, can often be so severe that they are debilitating and may also count as SMI. For these cases, we categorized "depression," and surveyors were trained to ask follow-up questions to record if it interfered with daily tasks. However, these limitations cannot completely account for depression that may be debilitating enough to be considered SMI.

Another population to account for, which seems to be the focus of some advocates, includes those who may hide their mental illness, e.g., those who answered "No" and did not report their mental health concerns, although they were formerly diagnosed, or those who were unwilling to share their symptoms. This limitation also affects other studies attempting to measure mental health concerns because of possibly stigmatizing concerns. Additionally, gathering information on the general population that hides their SMI would be equally as difficult. Addressing this issue would entail a new study focusing on those who may be mentally ill but fail to report it. This is an issue in any health survey relying on self-reporting.

We also counted 54 cases that reported symptoms of depression or anxiety that could be interpreted by diagnosticians as severely debilitating, and thus SMI. That would increase the total number of SMI to $14.2 \%$. While this is consistent with other studies, we believe this would overestimate our data on SMI because not all reports of depression are severe. Furthermore, feeling depressed about experiencing homelessness is situational and commonly rational, as voiced by Snow et al. (1986). On this topic, we also want to enunciate that we did not use the SCID or the GAF in combination as the NSDUH, which advocates call the "gold standard" of measuring mental illness (SAMHSA 2020). Future research should consider this because it is done with the general population or use another assessment tool (possibly the MINI due to its brevity) on the streets.

We also argue that funding for research on this subject heavily incentivizes a medicalized framework for analysis. Funding sources such as the National Institutes of Health (NIH) and Health and Human Services (HHS) cater to research interested in supporting a health purview. Thus, NIH and HHS -supported research biases policy, which in turn further medicalizes homeless individuals. Future research should also consider if those experiencing homelessness base their responses on desires for 
mental health services, indicating that they are acculturated to the service industry and thus provide the socially-desired response. This is especially important with increased homelessness due to job loss due to the COVID-19 pandemic.

\section{Conclusions}

Many sociologists have been mindful to consider the socially constructed environmental norms surrounding homelessness when researching this population. However, research suggests that efforts to improve and refine the methodologies currently used are still needed (Lee et al. 2010; NLCHP 2017). The COVID-19 pandemic will likely increase poverty and homelessness due to structural economic downturns, and policymakers should consider the exclusionary path to housing aid under current policies. Research on homelessness has only recently begun to acknowledge its limited scope and possible methodological biases, such as the tendency to target respondents who are visible to the public eye while ignoring more hidden homeless populations. In an annual review devoted to homelessness, Lee et al. (2010) state that "such [methodological] problems have spurred technical improvements and explicit attention to how aspects of research design shape results" (p. 503). It is in light of these methodological difficulties that this study was conducted.

The methodologies and findings presented in this paper represent a step forward in describing access to services and a more accurate understanding of the prevalence of serious mental illness among this vulnerable population. Those experiencing homelessness should not need to be severely mentally ill or otherwise disabled to be eligible for housing. We feel that medicalizing homelessness further stigmatizes individuals experiencing homelessness, but we do not intend to stigmatize homeless people who are experiencing mental illness or to demerit their challenges and deservingness. To be clear, the assertion that there is a "majority" of people experiencing homelessness who are mentally ill is fallacious. Prioritizing homeless services for those with SMI does a disservice for the bulk of those who are experiencing homelessness. Our findings also support various meta-analyses that point to structural causes of homelessness over individual pathologies. People who have lost their housing should not need to be mentally ill as a means to accumulate enough stigma to exchange for housing eligibility under HUD's Homeless Assistance Grants, which are also the only available avenues through HUD without a waiting list of many years, such as Section 8 housing. It is time we rethink how homeless housing assistance is provided. For example, New York City's ability to house homeless people in hotels and other units during the COVID-19 pandemic shows that this is possible if there is the political will to do so. Budget studies also show that housing first initiatives are more financially sound than relying on stays in emergency rooms, jails, and continuously engaging EMTs and police officers to manage homelessness (National Alliance to End Homelessness 2020).

Author Contributions: Paper was conceived and written together by C.S. and E.C. All authors have read and agreed to the published version of the manuscript.

Funding: This research received no external funding.

Acknowledgments: We thank David Snow, Leon Anderson, and Kim Hopper who saw early versions of this paper. Maura Fennelly, Daniel Jenks, Abby Ferdinando, Emma Vetter, and Ashli Melder provided suggestions on the writing of the paper. Angela Aidala, Teresa Gowan, and Kevin Fitzpatrick provided helpful guidance to the larger project that help inform our ethical and professional engagement with human subjects experiencing homelessness.

Conflicts of Interest: The authors declare no conflict of interest.

\section{References}

American Psychiatric Association. 2000. Diagnostic and Statistical Manual of Mental Disorders, 4th ed. Alington: APA. Anderson, Nelse. 1923. Hobohemia, the Home of the Homeless Man The Hobo. Chicago: University of Chicago Press. Aubry, Tim, Geoffrey Nelson, and Sam Tsemberis. 2015. Housing first for people with severe mental illness who are homeless: A review of the research and findings from the at home-Chez soi demonstration project. The Canadian Journal of Psychiatry 60: 467-74. [CrossRef] [PubMed] 
Aviña Cerecer, Gustavo. 2020. The Dispossessed of Necropolitics on the San Diego-Tijuana Border. Social Sciences 9: 91. [CrossRef]

Bogard, Cinthia. J. 2001. Claimsmakers and contexts in early constructions of homelessness: A comparison of New York City and Washington, DC. Symbolic Interaction 24: 425-54. [CrossRef]

Bratt, Rachel G., Michael E. Stone, and Chester Hartman, eds. 2006. A Right to Housing: Foundation for a New Social Agenda. Philadelphia: Temple University Press.

Braun, Sharon, and Jane Cox. 2005. Managed Mental Health Care: Intentional Misdiagnosis of Mental Disorders. Journal of Counseling and Development 83: 425-33. [CrossRef]

Campbell, Howard, and Josué G. Lachica. 2013. Transnational Homelessness: Finding a Place on the Us-Mexico Border. Journal of Borderlands Studies 28: 279-90. [CrossRef]

Canvin, Krysia, Chris Jones, Anneli Marttila, Bo Burström, and Margaret Whitehead. 2007. Can I risk using public services? Perceived consequences of seeking help and health care among households living in poverty: Qualitative study. Journal of Epidemiology \& Community Health 61: 984-89.

Castañeda, Ernesto. 2019. Building Walls: Excluding Latin People in the United States. Lanham: Lexington Books.

Castañeda, Ernesto, and Casey Chiappetta. 2020. Border Residents' Perceptions of Crime and Security in El Paso, Texas. Social Sciences 9: 24. [CrossRef]

Castañeda, Ernesto, Jonathan D. Klassen, and Curtis Smith. 2014. Hispanic and Non-Hispanic Homeless Populations in El Paso, Texas. Hispanic Journal of Behavioral Sciences 36: 488-505. [CrossRef]

Castañeda, Ernesto, Kevin Beck, and Josue Lachica. 2015. Walking through Contemporary North American Barrios: Hispanic Neighborhoods in New York, San Diego, and El Paso. In Walking in Cities: Quotidian Mobility as Urban Theory, Method, and Practice. Edited by Evrick Brown and Timothy Shortell. Philadelphia: Temple University Press.

Chen, Patricia M. 2019. Housing First and Single-Site Housing. Social Sciences 8: 129. [CrossRef]

City Mayors Statistics. 2010. The Largest U.S. Cities Ranked 1 to 100. Available online: http://www.citymayors. com/gratis/uscities_100.html (accessed on 12 August 2020).

Comar, Scott. 2011. Border Junkies: Addiction and Survival on the Streets of Juárez and El Paso. Austin: University of Texas Press.

Conrad, Peter. 1992. Medicalization and social control. Annual Review of Sociology 18: 209-32. [CrossRef]

Culhane, Dennis P., Stephen Metraux, and Trevor Hadley. 2002. Public Service Reductions Associated with Placement of Homeless Persons with Severe Mental Illness in Supportive Housing. Housing Policy Debate 13: 107-63. [CrossRef]

Dear, Michael J., and Jennifer R. Wolch. 2014. Landscapes of Despair: From Deinstitutionalization to Homelessness. Princeton: Princeton University Press.

Dordick, Gwendolyn A. 2002. Recovering from homelessness: Determining the "quality of sobriety" in a transitional housing program. Qualitative Sociology 25: 7-32. [CrossRef]

Fazel, Seena, Vivek Khosla, Helen Doll, and John Geddes. 2008. The prevalence of mental disorders among the homeless in western countries: Systematic review and meta-regression analysis. PLoS Medicine 5: e225. [CrossRef] [PubMed]

Fischer, Pamela J. 1989. Estimating prevalence of alcohol, drug, and mental health problems in the contemporary homeless population: A review of the literature. Contemporary Drug Problems 16: 333-90.

Frankfort-Nachmias, Chava, and Anna Leon-Guerrero. 2017. Social Statistics for a Diverse Society, 8th ed. Thousand Oaks: SAGE.

Gaetz, Stephen. 2020. Making the Prevention of Homelessness a Priority: The Role of Social Innovation. American Journal of Economics and Sociology 79: 353-81. [CrossRef]

Goffman, Erving. 1962. Asylums: Essays on the Social Situation of Mental Patients and Other Inmates. Chicago: Aldine Publishing Company.

Golembiewski, Elizabeth, Dennis P. Watson, Lisa Robison, and John W. Coberg II. 2017. Social Network Decay as Potential Recovery from Homelessness: A Mixed Methods Study in Housing First Programming. Social Sciences 6: 96. [CrossRef] [PubMed]

Gowan, Teresa. 2010. Hobos, Hustlers, and Backsliders: Homeless in San Francisco. Minneapolis: University of Minnesota Press. 
HEARTH. 2015. HEARTH: Defining 'Chronically Homeless'. Federal Register: The Daily Journal of the United States 80: 75791-806. Available online: https://www.gpo.gov/fdsys/pkg/FR-2015-12-04/pdf/2015-30473.pdf (accessed on 12 August 2020).

Hopper, Kim, Marybeth Shinn, Eugene Laska, Morris Meisner, and Joseph Wanderling. 2008. Estimating Numbers of Unsheltered Homeless People through Plant-Capture and Postcount Survey Methods. American Journal of Public Health 98: 1438-42. [CrossRef]

HUD. 2013. Annual Homeless Assessment Report to Congress. Washington: Housing and Urban Development. Available online: https://files.hudexchange.info/reports/published/CoC_PopSub_Nat1TerrDC_2013.pdf (accessed on 12 August 2020).

HUD. 2018. Model PIT Survey. Available online: https:/files.hudexchange.info/resources/documents/ModelSheltered-Night-of-Count-PIT-Survey.pdf (accessed on 13 August 2020).

HUD 2007-2018. 2019. Annual Homeless Assessment Report to Congress. Washington: Housing and Urban Development. Available online: https://www.hudexchange.info/resource/3031/pit-and-hic-data-since-2007/ (accessed on 12 August 2020).

HUD. 2019. Homelessness Prevention and Rapid Re-Housing Program. Available online: https://www. hudexchange.info/programs/hprp/ (accessed on 12 August 2020).

Huey, Laura, Georgios Fthenos, and Danielle Hryniewicz. 2012. "I Need Help and I Know I Need Help. Why Won't Nobody Listen to Me?" Trauma and Homeless Women's Experiences with Accessing and Consuming Mental Health Services. Society and Mental Health 2: 120-34. [CrossRef]

Jackson, Alphonso. 2007. The Annual Homeless Assessment Report to Congress; Washington: U.S. Department of Housing and Urban Development Office of Community Planning and Development.

Jans, Lita, Susan Stoddard, and Lewis Kraus. 2004. Chartbook on Mental Health and Disability in the United States; Washington: U.S. Department of Education, National Institute on Disability and Rehabilitation Research.

Jencks, Christopher. 1994. The Homeless. Cambridge: Harvard University Press.

Johnson, Guy, and Chris Chamberlain. 2008. Homelessness and Substance Abuse: Which comes first? Australian Social Work 61: 342-56. [CrossRef]

Johnson, Guy, and Chris Chamberlain. 2011. Are the homeless mentally ill? Australian Journal of Social Issues 46: 29-48. [CrossRef]

Kessler, Ronald C., Wai Tat Chiu, Olga Demler, and Ellen E. Walters. 2005. Prevalence, severity, and comorbidity of twelve-month DSM-IV disorders in the National Comorbidity Survey Replication. Archives of General Psychiatry 62: 617-27. [CrossRef] [PubMed]

Kozol, Jonathan. 1988. Rachel and Her Children: Homeless Families in America. New York City: Broadway Books.

Lee, Barrett, Kimberly Tyler, and James Write. 2010. The new homelessness revisited. The Annual Review of Sociology 36: 501-21. [CrossRef] [PubMed]

LOCUS. 2020. American Association of Community Psychiatrists. Erie: Deerfield Behavioral Health, Inc. Available online: https://cchealth.org/mentalhealth/pdf/LOCUS.pdf (accessed on 12 August 2020).

Loza, Oralia, Ernesto Castañeda, and Brian Diedrich. 2017. Substance Use by Immigrant Generation in a U.S.-Mexico Border City. Journal of Immigrant and Minority Health 19: 1132-39. [CrossRef]

Lyon-Callo, Vincent. 2000. Medicalizing Homelessness: The Production of Self-Blame and Self-Governing within Homeless Shelters. Medical Anthropology Quarterly 14: 328-45. [CrossRef]

Martinez, Tia, and Martha Burt. 2006. Impact of permanent supportive housing on the use of acute care health services by homeless adults. Psychiatric Services 57: 992-99. [CrossRef]

Moya, Eva Margarita, Silvia M. Chavez-Baray, Jacqueline Loweree, Brian Mattera, and Nahomi Martinez. 2017. Adults Experiencing Homelessness in the Us-Mexico Border Region: A Photovoice Project. Frontiers in Public Health 5: 113. [CrossRef]

Homeless Assistance Reauthorization. 2019. Highlights of the HEARTH. Available online: https://endhomelessness. org/resource/hearth-act-section-by-section-analysis/ (accessed on 12 August 2020).

National Alliance to End Homelessness: 2020 Edition. 2020. State of Homelessness. Available online: https://endhomelessness.org/homelessness-in-america/homelessness-statistics/state-ofhomelessness-2020/ (accessed on 12 August 2020).

National Coalition for the Homeless. 2013. The State of Homelessness in America 2012. Washington: National Coalition for the Homeless. 
NLCHP. 2017. Don't Count on it: How the HUD Point-in-Time Count Underestimates the Homelessness Crisis in America. In National Law Center on Homelessness and Poverty. Washington: NLCHP. Available online: https://nlchp.org/wp-content/uploads/2018/10/HUD-PIT-report2017.pdf (accessed on 12 August 2020).

Osborne, Melissa. 2018. Who Gets 'Housing First'? Eligibility Determination in an Era of Housing First Homelessness. Journal of Contemporary Ethnography 48: 402-28. [CrossRef]

Padgett, Deborah, Benjamin Henwood, and Sam Tsemberis. 2016. Housing First: Ending Homelessness, Transforming Systems, and Changing Lives. Oxford: Oxford University Press.

Perl, Libby. 2017. The HUD Homeless Assistance Grants: Programs Authorized by HEARTH Act. Washington: Congressional Research Service.

Ranasinghe, Prashan. 2017. Helter-Shelter: Security, Legality, and an Ethic of Care in an Emergency Shelter. Toronto: University of Toronto Press.

Rossi, Peter H. 1990. The old homeless and the new homelessness in historical perspective. American Psychologist 45: 954. [CrossRef]

Rossi, Peter H. 1991. Down and out in America: The Origins of Homelessness. Chicago: University of Chicago Press.

Rossi, Peter, James D. Wright, Gene A. Fisher, and Georgina Willis. 1987. The urban homeless: Estimating composition and size. Science. Science 235: 1336-41. [CrossRef]

SAMHSA. 2020. Results from the 2018 National Survey on Drug Use and Health: Detailed Tables; Appendix 3.4.7.3. Rockville: Center for Behavioral Health Statistics and Quality, Substance Abuse and Mental Health Services Administration. Available online: https://www.samhsa.gov/data/ (accessed on 12 August 2020).

Sheehan, David V., Juris Janavs, Roxy Baker, K. Harnett-Sheehan, E. Knapp, and M. Sheehan. 2006. Mini International Neuropsychiatric Interview English 5.0.0. Tampa: University of South Florida.

Shlay, Anne, and Peter Rossi. 1992. Social science research and contemporary studies of homelessness. Annual Review of Sociology 18: 129-60. [CrossRef]

Siorda, Carlos, Curtis Smith, and Ernesto Castañeda-Tinoco. 2014. A Geographically-Aware Multilevel Analysis on the Association between Atmospheric Temperature and the 'Emergency and Transitional Shelter Population. Human Geographies 8: 5-16. [CrossRef]

Smith, Curtis, and Leon Anderson. 2018. Fitting stories: Outreach worker strategies for housing homeless clients. Journal of Contemporary Ethnography 47: 535-50.

Smith, Curtis, and Ernesto Castañeda-Tinoco. 2019. Improving Homeless Point-In-Time Counts: Uncovering the Marginally Housed. Social Currents 6: 91-104. [CrossRef]

Snow, David, and Leon Anderson. 1993. Down on Their Luck: A Study of Homeless Street People. Berkeley: University of California Press.

Snow, David, and Leon Anderson. 2001. Inequality and the self: Exploring connections from an interactionist perspective. Symbolic Interaction 24: 395-406.

Snow, David, Susan Baker, Leon Anderson, and Michael Martin. 1986. The myth of pervasive mental illness among the homeless. Social Problems 33: 407-23. [CrossRef]

Snow, David, Leon Anderson, and Paul Koegel. 1994. Distorting tendencies in research on the homeless. American Behavioral Scientist 37: 461-75. [CrossRef]

Snow, David, Susan Baker, and Leon Anderson. 2014. On the precariousness of measuring insanity in insane contexts. Social Problems 35: 192. [CrossRef]

SPDAT. 2020. Service Prioritization Decision Assistance Tool. Orgcode.com. Available online: https://www. orgcode.com/products (accessed on 12 August 2020).

Stern, Mark. 1984. The emergence of the homeless as a public problem. The Social Service Review 58: 291-301. [CrossRef]

Stuart, Forrest. 2016. Down, Out, and Under Arrest: Policing and Everyday Life in Skid Row. Chicago: University of Chicago Press.

Susser, Ezra, Sarah Conover, and Elmer Struening. 1990. Mental illness in the homeless: Problems of epidemiologic method in surveys of the 1980s. Community Mental Health Journal 26: 391-414. [CrossRef]

Tan, Philip, and Ellen Ryan. 2001. Homeless Hispanic and Non-Hispanic Adults on the Texas-Mexico Border. Hispanic Journal of Behavioral Sciences 23: 239-49. [CrossRef]

Torrey, Edwin Fuller. 1988. Nowhere to Go: The Tragic Odyssey of the Homeless Mentally Ill. New York: Harper and Row. 
Wasserman, Jason, and Jeffrey Clair. 2010. At Home on the Street; People Poverty and a Hidden Culture of Homelessness. Boulder: Lynne Rienner Publishers.

Willse, Craig. 2015. The Value of Homelessness: Managing Surplus Life in the United States. Minneapolis: University of Minnesota Press.

Wong, Yin-Ling, Jung Min Park, and Howard Nemon. 2006. Homeless service delivery in the context of continuum of care. Administration in Social Work 30: 67-94. [CrossRef]

Wright, Eric R., Brandon K. Attell, and Erin Ruel. 2017. Social Support Networks and the Mental Health of Runaway and Homeless Youth. Social Sciences 6: 117. [CrossRef]

(c)

(C) 2020 by the authors. Licensee MDPI, Basel, Switzerland. This article is an open access article distributed under the terms and conditions of the Creative Commons Attribution (CC BY) license (http://creativecommons.org/licenses/by/4.0/). 